\title{
On Surface Damage of Polymer Coated Sheet Metals during Forming
}

\author{
Zalak Purohit and Ying Zhang \\ Department of Mechanical Engineering \\ Texas A\&M University \\ College Station, Texas, USA \\ Jyhwen Wang* \\ Department of Engineering Technology and Industrial Distribution \\ Department of Mechanical Engineering \\ Texas A\&M University \\ College Station, Texas, USA
}

\begin{abstract}
Prepaint sheet metals are widely used in building construction, packaging, appliance, transportation and automotive industries. Due to tooling contact, damage of polymer coating can occur during sheet metal forming processes. This paper presents an investigation of surface damage of polyvinylidene flouride (PVDF) and polypropylene (PP) coatings in various forming conditions. Strip drawing experiments were conducted to test coatings subjected to bending under tension with sliding contact. The experimental results and numerical simulations suggest that coating damage is commonly caused by low coating strength, high contact pressure, and poor lubrication. The presented experimental approach can be used to facilitate tooling design and lubricant selection in forming prepaint sheet metals.
\end{abstract}

\section{KEYWORDS}

Prepaint Sheet Metal, Coating Damage, Friction, Lubrication

* Corresponding author: Jyhwen Wang, Email: jwang@tamu.edu, Tel: 979-845-4903 


\section{Introduction}

Sheet metals are widely used in many industries because of their high ductility and various range of mechanical strengths compared to other materials such as ceramics and polymers. The prepaint coatings on the metal surface provide glossy surface finish and protection against corrosion. However, during forming process, surface damage in the forms of scratches and loss of glossiness on the coating can occur [1]. Thus, it is of significant interest to develop proper metal forming techniques for applications of prepaint sheet metals.

Friction condition between the die and workpiece plays an important role on the results of sheet metal forming process. To investigate the flow behavior of the workpiece material, simulative forming tests such as cup test [2,3], bending under tension test $[4,5]$, punch-stretch test [6,7], drawbeads test [8,9], strip deep drawing test [10], and deep drawing test [11] were developed. Based on these testing methods, efforts have been made to evaluate deformation behavior of sheet metals under different friction and lubrication conditions. While the studies have resulted in many advances in the field of sheet metal forming, the quality of workpiece surface, particularly polymer coatings, after forming has not been a main focus in these investigations.

Comprehensive friction studies on polymer have been carried out in the past. Two most commonly applied testing methods are pin-on-disk test and scratch resistant test. The pin-on-disk apparatus has been used to study the wear of polymer $[12,13]$. The scratch test was mainly designed and conducted to investigate scratch damage mechanisms of polymers and soft coatings on hard substrates [14-16]. It can be observed that when used to test polymer coatings, neither these tests simulate the large plastic deformation of sheet metal substrates.

Few results are available from the studies of polymer coating damage in sheet metal forming. Tekkaya et al. [17] used the hemispherical dome test to investigate the reduction of glossiness of organic coating after forming. The change of glossiness was correlated to the major and minor strains and presented in the format similar to that of forming limit diagram (FLD). While the cause of the glossiness reduction was not explored, it is 
believed that the change of gloss property was not due to damage caused by tooling contact but due to realignment of the polymer chains. Carlsson $[18,19]$ investigated the tribological performance of thin organic coatings in sheet metal forming. Various tests, including bending under tension, ball-on-disk, and modified scratch tests were conducted. The surfaces of the tested specimens were characterized by scanning electron microscopy (SEM), energy dispersive X-ray spectroscopy (EDS), auger electron spectroscopy (AES), and optical interference profilometer techniques. The work mainly comprises tribo testing and post test characterization without addressing specific issues in tooling design and lubrication condition that can affect the quality of coating surface after forming.

For a given prepaint product, it is often desired to obtain its process limit such that the proper die radius, clamping load, and lubrication condition can be selected to prevent surface damage. The present work is motivated by the need for a better understanding of process tribology in forming prepaint sheet metals. A modified bending under tension test was used to evaluation several coatings under different die radii and lubrication conditions. Friction between the die radius and the workpiece was calculated from the experimental data. The coating property before and after forming was evaluated with nano-indentation. The tested specimens were examined for surface damage with an optical microscope. Numerical simulation of the bending under tension test was conducted to understand the damage mechanism of the polymer coatings.

\section{Experiments}

Bending under tension is a well-established friction test method [20]. The test was developed to simulate the contact between the die and the workpiece surfaces and the deformation of a sheet metal at the die radius. In this investigation, the experimental setup was developed using a draw bench. Prepaint specimen and lubricant used in the experiments were provided by a collaborator in industry. The performance of different coatings under different die radii and lubrication conditions was investigated in order to correlate the testing parameters to the surface quality after forming.

\subsection{Experimental Set-up and Friction Model}


A schematic of the bending under tension test is shown in Fig. 1. The system consists of a linear actuator (draw-bench), two load cells (Load Cell I and II), a clamping mechanism, and a die and die holder assembly. The specimen is loaded with $90^{\circ}$ bend and secured on the die over which the specimen can stretch and slide. One end of the specimen is clamped between two back plates to provide back tension. The iLoad Mini load cell (Load Cell II) with a capacity of $889.6 \mathrm{~N}$ and accuracy of $2.2 \mathrm{~N}$ is used to measure the clamping load. The other end of the specimen is attached to RAS1 S-Beam (Load Cell I) that is bolted to the actuator of the draw bench. Load Cell I has a capacity of $8896.4 \mathrm{~N}$ and accuracy of $1.8 \mathrm{~N}$, and is used to measure the drawing/pulling force. The die radius can be changed by replacing the die insert in the holder. While the die is a freely rotating cylinder in a typical bending under tension tester, the die is fixed (no rotation allowed) in the present experimental set-up to simulate the practical forming processes prescribed by industry. The developed testing apparatus is shown in Fig. 2.

To determine the coefficient of friction at the die-workpiece interface, a friction model that takes into account of the contact angle and bending force is adopted [21]. The coefficient of friction can be calculated from:

$$
\mu_{d}=\frac{2}{\theta}\left(\frac{F_{1}-F_{2}-F_{b}}{F_{1}+F_{2}}\right)
$$

where $\mu_{d}$ is the coefficient of friction at die and prepaint sheet metal interface, $\theta$ is the wrap angle ( $\theta=90^{\circ}$ in the present case), $F_{1}$ is the pulling force from Load Cell I measurement, $F_{2}$ is the back tension from clamping, and $F_{b}$ is the bending force. The back tension is calculated from:

$$
F_{2}=\mu_{b} N
$$

where $\mu_{q}$ is the coefficient of friction between the clamping plate and the specimen, and $N$ is the clamping load that can be obtained from Load Cell II. Note that the friction $\mu_{b}$ can be measured using a simple strip drawing test. The bending force can be calculated from [22]: 


$$
F_{b}=\frac{\sigma_{y} t^{2} W}{2 r}
$$

where $\sigma_{y}$ is the yield strength, $w$ is the width, $t$ is the thickness of the strip, and $r$ is the die radius.

\subsection{Testing Parameters}

Four different prepaint materials were provided by collaborators from industry. The first three materials, identified as Material \#1 to Materials \#3, were coated with polyvinylidene flouride (PVDF) resin (the contact surface) on top of polyester primer. The substrates were either aluminum or galvanized steel. Material \#3 was embossed with surface texture. The average number of impression was about 8.7 per square centimeter. The impression depth ranged from $0.2 \mathrm{~mm}$ to $0.41 \mathrm{~mm}$. These materials were commercial products used for metal roofing application. Material \#4 had a polypropylene coating on tin-coated steel substrate. The material was not a commercial product and was obtained from a pilot coating line. A main interest was to compare the performance of this coating with the commercial PVDF coatings. A shear was used to cut the materials into specimens having $38.1 \mathrm{~mm}$ in width. Table 1 summarizes the test materials.

Bending under tension experiments were conducted using different die radii under three different lubrication conditions. In this study, the severity of bending at the die radius was characterized by the normalized die radius (or normalized bending ratio), the

die radius to the specimen thickness ratio. A number of die radii were selected to obtain the normalized bending ratios of 1T, 5T, and 10T where $\mathrm{T}$ indicates specimen thickness. A surface profilometer was used to evaluate the surface roughness of the dies to make sure that all the dies of different radii having a similar surface roughness. For lubrication, emulsion of 1\% Zurn aquasol oil in water is currently used in industry. It was reported by the industrial collaborator that such condition was ineffective and resulted in coating damage at times. Conditions of applying 100\% Zum oil, 1\% oil in water emulsion, and no lubrication were prescribed in this study to investigate the effect of lubrication on coating surface damage. 
In all the tests, the specimen was pulled by an actuator with constant speed of 8 $\mathrm{mm} / \mathrm{sec}$. The initial clamping load was set at $750 \mathrm{~N}$. Before conducting each test, proper care was taken to remove any dirt or particles from the die and specimen surfaces. After testing, the coefficient of friction between the contact surfaces was calculated from the front and back tension forces. Optical microscope was used to examine the surfaces of the specimen before and after the test. Nano-indentation technique was also used to measure the properties of the coating.

\section{Experimental results}

The real time pulling force and back tension force were obtained from Load Cell I and Load Cell II, respectively. While the back tension was kept at about 133 N, Load Cell I recorded different pulling forces for different normalized die radii and lubrication conditions. Fig. 3 shows the pulling forces (averaged from 3 trials) for Material \#1 under 1T, 5T, and 10T bends with no lubricant applied. It can be observed that as the normalized die radius decreases, the force required to draw the specimen around the die radius increases. This can be attributed to the increase in bending force with a decreased die radius as shown in Eq. (3).

\subsection{Effects of die radius}

Based on the friction model in [21], Eq. (1) was used to calculate the sliding friction at the die surface-workpiece interface. Fig. 4 shows the real time coefficient of friction of the 5T and 10T radii for Material \#1 tested without lubricant. It can be observed that the coefficient of friction was not constant throughout the test, demonstrating the dynamic nature of friction in sheet metal forming process. The variability could be caused by minor changes in specimen thickness, property, and surface condition. During the deformation process, the instantaneous real contact area between the die and the specimen could also change and lead to variation in coefficient of friction within a test. Due to variations in many contributing factors, there was also noticeable variation in friction between the two tests with the same bending radius. The effect of normalized die 
radius, however, can be clearly observed. The coefficient of friction decreases as die radius increases. It is believed that the higher coefficient of friction was due to an increase in contact pressure. This is further examined in numerical simulations later.

For visual inspection, microscope images of the coating surface were taken before and after testing. Fig. 5(a) shows the surface of Material \#1 before testing; and Figs. 5(b) to 5(d) show the surfaces of the same material tested with $10 \mathrm{~T}, 5 \mathrm{~T}$, and $1 \mathrm{~T}$ die radii at dry condition (no lubrication), respectively. For 10T and 5T die radii, no distinct scratch mark was observed. Significant damage on coating surface can be seen for the same material drawn over $1 \mathrm{~T}$ die radius. That is, higher contact friction can lead to more severe coating damage. This result is also observed in other experiments.

\subsection{Effects of lubrication}

A wide range of metalworking lubricants are available in industry. For stamping of prepaint sheet metal roofing panels, $1 \%$ oil in water emulsion was used. However, it is not clear if the lubrication condition is sufficient for different die radii and different prepaint products. Therefore it is of interest to investigate the effect of lubrication on the quality of coating surface after forming. In this study, three lubrication conditions including $100 \%$ Zurn oil, 1\% Zurn oil in water emulsion, and no lubrication were selected to conduct bending under tension tests.

The coefficient of friction measurement of Material \#1 drawn over 5T die radius is shown in Fig. 6. It is clear that friction is highest under dry condition, followed by $1 \%$ oil in water emulsion and $100 \%$ oil lubrication. It is interesting to note that, in the case of $1 \%$ emulsion, the friction increases with time during the test. This could be due to the less viscous nature of the diluted lubricant. It was observed that, with time, the lubricant was squeezed out of the contact area leading to increased coefficient of friction.

Microscope images of the coating surface of Material \#1 drawn over 5T die radius are shown in Figs. 7(a) to 7(c). It can be seen that under the 100\% oil lubrication condition, the coating surface appears glossier with less obvious scratch than the surfaces formed under other two lubrication conditions. It should also be noted that the scratch mark on Fig. 7(a) could be caused by the high friction observed in the beginning of the test. 


\subsection{Effects of Material}

The severity of coating surface damage heavily depends on the property of the coating. To evaluate the performance of different coatings, tests were conducted on materials drawn over 1T, 5T, and 10T radii under different lubrication conditions. Figs. 8 to 10 show the coating surface after forming under no lubricant condition for Materials \#1, \#3, and \#4, respectively.

The coatings on Material \#1 and \#3 are both PVDF. From Fig. 9, it can be observed that Material \#3 has significant localized damage (pointed by the arrows in Fig. 9(a)) as the textured surface has a smaller real contact area thus a higher contact stress compared to the non-textured surface. Since the strength/hardness of polypropylene is lower than that of PVDF, the surface damage of Materials \#4 was more significant, as can be seen in Fig. 10, than the damage on PVDF.

Nano-indentation test was carried out on the coating surface after specimens were drawn over different die radii. The indentation hardness results (measured in GPa) of Material \#1 obtained before and after forming are shown in Fig. 11. It is observed that the nano-indentation results can vary significantly due to probe placement. This is especially true for the coating with color pigment, as the probe could come in contact with pigment particles and produce high hardness readings. Exluding the outliers (hardness reading above $0.3 \mathrm{GPa}$ ), it is observed that the coating exhibits strain softening behavior. The averaged indentation hardness decreases with deacreased die radius (hardness of 0.200 , $0.216,0.190$, and $0.157 \mathrm{GPa}$ for no deformation, 10T, 5T, and $1 \mathrm{~T}$ specimens, respectively). This implies that the scratch resistance of the formed prepaint products is reduced and can be different due to different degree of strain softening.

\section{Numerical simulation results}

The experimental results show that the coating surface damage is strongly related to high coefficient of friction. As high contact pressure can lead to high coefficient of friction, it is of interest to demonstrate that the coating damage is mainly due to high 
contact stress. Finite element analysis (FEA) was performed to simulate the bending under tension test. Numerical simulation was used to observe the trend to better understand the effect of friction and the development of contact pressure acting on the coating surface.

\subsection{Numerical Simulation Models}

The plane strain FEA simulations of the bending under tension test were performed using ABAQUS. The die and the clamping plates were modeled as rigid body, and the specimen was modeled as a deformable body made of metal and polymer layers. The properties of the aluminum substrate were obtained from a tensile test (Fig. 12) and the constitutive behavior was described by the paired stress-strain data. For polymer coating, the elastic-perfect plastic model was used. The yield strength of the PVDF coating was $48 \mathrm{MPa}$. As depicted in Fig. 13 (deformed specimen shown), the die and the clamping plates were fixed in space, and the prepaint specimen was prescribed with linear displacement control such that the specimen was pulled towards the left. The clamping load was kept constant. Die radii of different values were modeled to obtain the normalized bending ratios of 3T, 5T and 10T. Hard surface contact between the contact surfaces with different coefficient of friction values was prescribed.

\subsection{Pulling Force and Friction}

In the simulation, the specimens were drawn over $3 \mathrm{~T}, 5 \mathrm{~T}$, and $10 \mathrm{~T}$ die radii with the coefficient of friction assigned as the averaged experimental value at 0.224 . The reaction forces at the pulling end of the strip were recorded and are shown in Fig. 14. In each case, the pulling force went up rapidly in the beginning and then became almost stable after some time. The results also show that the pulling force increases with decreased die radius. Comparing the simulation result of Material \#1 over $5 \mathrm{~T}$ bend radius with no lubrication in Fig. 14 to the experimental result as shown in Fig. 3, it can be observed that the simulation and experimental results are in good agreement. 
The influence of coefficient of friction between the die and the workpiece on the pulling force is shown in Fig. 15. In these simulations, 10T die radius was used and constant friction of $0.09,0.15,0.244$, and 0.344 was assigned in each simulation. As expected, a higher coefficient of friction led to a higher pulling force. This is also in agreement with the experimental observation.

\subsection{Contact Pressure}

It is believed that the coating damage is due to sliding of coating surface under high contact pressure. Thus, the maximum contact pressure during the forming process should be a critical concern. Simulations were conducted to find the contact pressure distribution along the die-workpiece interface. Figs. 16 (a) and (b) show the contact pressure intensity along the coating surface on $5 \mathrm{~T}$ die radius at two different time instances $(0.04 \mathrm{sec}$. and $0.1 \mathrm{sec}$. simulation time). The node number on the abscissa indicates the location of the workpiece surface from exit end to the entry end in the experiment (corresponding to the sequence from A through D in Fig. 13). It is found the peak contact pressure was located near the entry and the exit ends of the contact zone in both cases. The result was consistent with the contact stress distribution of the strip drawing die reported by Henning and discussed in [23] related to the wear behavior of the forming tools. Fig. 16(a) shows that the peak contact pressure was around Node 58 at $0.04 \mathrm{sec}$. At that location (Node 58), the pressure dropped to zero at $0.1 \mathrm{sec}$. as shown in Fig. 16(b). This indicates the node was pulled out of the contact zone. Therefore, when investigating the maximum contact pressure, the entire load history should be evaluated.

Fig. 17 shows the nodal contact pressure at time $t=0.08 \mathrm{sec}$. for material drawn over $3 \mathrm{~T}, 5 \mathrm{~T}$, and $10 \mathrm{~T}$ die radii. Note that $\mathrm{B}$ on the abscissa corresponds to the location near the exit end of the contact zone as shown in Fig. 13. Locations $C(3 T), C(5 T)$, and $C(10 T)$ represent the entry ends for bending radii of $3 \mathrm{~T}, 5 \mathrm{~T}$, and $10 \mathrm{~T}$, respectively. It can be seen that the smallest die radius (3T) had a shortest contact length and resulted in the highest peak contact pressure. The result is consistent with the observed friction behavior where small die radius causes friction to increase. 


\section{Conclusions}

In the present work, surface damage of polymer coated sheet metals during forming was investigated. A bending under tension experimental apparatus was built to simulate the deformation of sheet metals at the die radius. Experiments were conducted using different die radii and lubrication conditions on different prepaint sheet metals. Numerical simulations were also conducted to analyze and understand the contact and friction behavior of the die and coating interface. The investigation leads to the following conclusions and recommendations:

1. Bending under tension test is an effective method for evaluating the coating performance in forming of prepaint sheet metals. From the experiments, it was observed that small normalized die radius and poor lubrication condition can leave significant scratch marks on polymer coating surfaces. It was also found that soft polymer such as polypropylene can be easily damaged during forming.

2. It was observed experimentally that the coefficient of friction increases with decreased die radius. Finite element simulation also showed that small die radius can lead to high contact pressure. Thus, high friction and high contact pressure can often cause coating surface damage.

3. Lubrication condition can change during sheet metal forming process. The practice of applying $1 \%$ oil in water emulsion was not sufficient when die radius is small. With small die radius, the oil in water emulsion is squeezed out due to high contact pressure. A higher concentration of metalworking fluid in emulsion is recommended to prevent surface damage.

4. Textured prepaint material has small true contact area. As such, the contact stress is significantly increased. The condition can easily lead to coating damage.

5. While the deformed materials may not have apparent surface damage, the coating can soften after forming as indicated in the nano-indentation tests. Further investigation into the scratch resistant of coating after deformation is recommended.

\section{Acknowledgement}


This material is based upon work supported by the National Science Foundation under Grant No. CMMI 0448789. The authors would like to thank Robert Barber and Bright Wadja for their assistance in conducting the experiments.

\section{References}

[1] van den Bosch MJ, Schreurs PJG., Geers MGD. Identification and characterization of delamination in polymer coated metal sheet. Journal of the Mechanics and Physics of Solids 2008; 56/11: 3259-76.

[2] Chung SY, Swift HW. Cup drawing from a flat blank: Part I. Experimental investigation. Proceedings of the Institution of Mechanical Engineers 1951; 165: 199-211.

[3] Atala H. Effect of differential lubrication on the cup drawing of mild steel blanks. Wear 1990; 39: 171-6.

[4] Littlewood M, Wallace JF. The effect of surface finish and lubrication on the friction variation involved in the sheet-metal-forming process. Sheet Metal Ind. 1964; 41:925-30.

[5] Vallance DW, Matlock OK. Application of the bending-under-tension friction test to coated sheet steels. Journal of Materials Engineering and Performance $1992 ; 1$ : 685-93.

[6] Ghosh AK. A method for determining the coefficient of friction in punch stretching of sheet metals. Journal of Mechanical Science 1977; 19: 457-70.

[7] Fox RT, Maniatty AM, Lee D. Determination of friction coefficient for sheet materials under stretch-forming condition. Metallurgical and Materials Transactions A 1989; 20/10: 2179-82.

[8] Nine, HD. Drawbead forces in sheet metal forming. Mechanics of Sheet Metal Forming, Plenum Press 1978; 179-203.

[9] Hou YK, Yu ZQ. Surface topography evolvement of galvanized steels in sheet metal forming. Transaction of Nonferrous Metals Society of China 2009; 19: 30510. 
[10] Schmoeckel D, Frontzek H, von Finckenstein E. Reduction of wear on sheet metal forming tools. CIRP Annals-Manufacturing Technology 1986; 35: 195-8.

[11] Kaftanoglu B. Determination of coefficient of friction under conditions of deep drawing and stretch forming. Wear 1973; 25:177-88.

[12] Robertson WG, Spillman DT. The hydrodynamics of flat contacts: friction studies in the pin and disc machine. Proceeding of the Institution of Mechanical Engineers 1965; 180: 49-60.

[13] Larsen TO, Andersen TL. Pin-on-disk apparatus for tribological studies of polymeric materials. Industrial Lubrication and Tribology 2009; 61/4: 203-8.

[14] Tabor D. The physical meaning of indentation and scratch hardness. British Journal of Applied Physics 1956; 7: 159-66.

[15] Jiang H, Browning R, Sue HJ. Understanding of scratch-induced damage mechanisms in polymers. Polymer 2009; 50: 4056-65.

[16] Browning RL, Jiang H, Sue HJ. Scratch behavior of polymeric materials. Tribology and Interface Engineering Series 2008; 55: 354-73.

[17] Tekkaya A, Trompeter M, Pham HD. On the reduction of the gloss property of organic coated sheet metal after foming. Production Engineering 2010; 10.1007/s11740-010-0215-8.

[18] Carlsson P. Surface engineering in sheet metal forming. Ph.D. dissertation, Acta Universitatis Upsaliensis Uppsala, Sweden; 2005..

[19] Carlsson P, Bexell U, Olsson M. Tribological behavior of thin organic permanent coatings deposited on hot-dip coated steel sheet-a laboratory study. Surface and Coating Technology 2000; 132: 169-80.

[20] Andreasen JL, Olsson DD, Chodnikiewicz K, Bay N. Bending under tension test with direct friction measurement. Proceedings of the Institution of Mechanical Engineers, Part B: Journal of Engineering Manufacture 2005; 220:73-80.

[21] Wilson WRD, Malkani HG, Saha PK. Boundary friction measurements using a new sheet metal forming simulator. Trans. NAMRI/SME 1991; 37-42.

[22] Swift HW. Plastic bending under tension. Engineering 1948; 166: 333-59. 
[23] Muller C, Groche P, Engels M. Wear behavior of sheet metal forming tools made from nodular cast iron mechanical surface treatments. Transactions of NAMRI/SME 2010; 38: 531-8. 


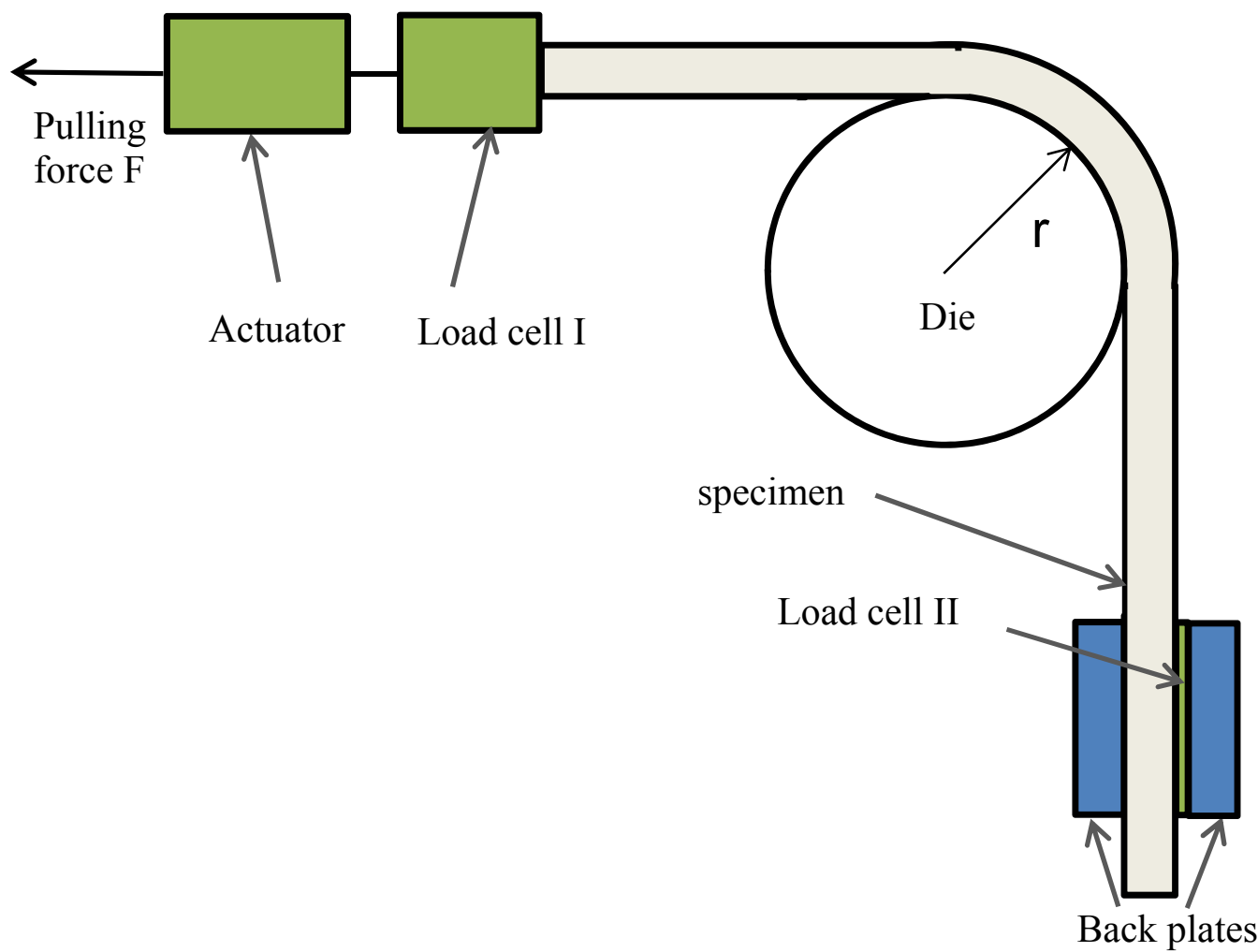

Fig. 1. Experimental set-up of bending under tension test.

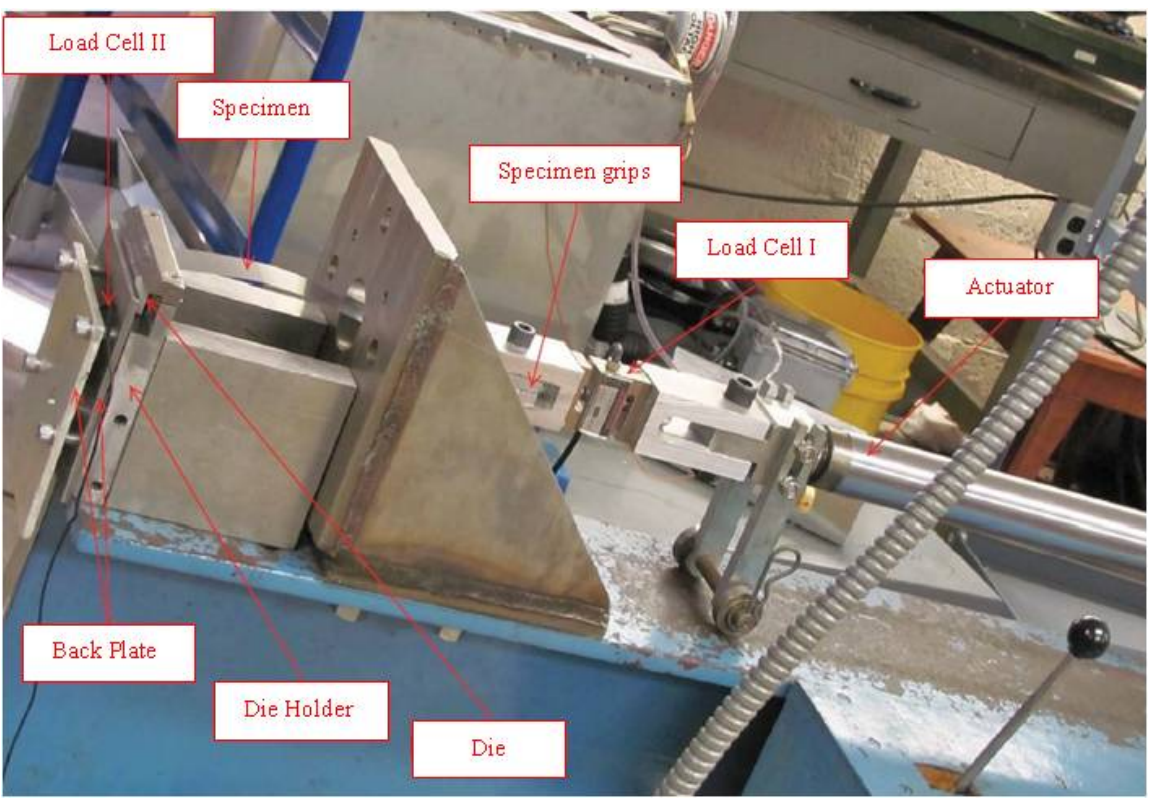

Fig. 2. Bending under tension apparatus. 


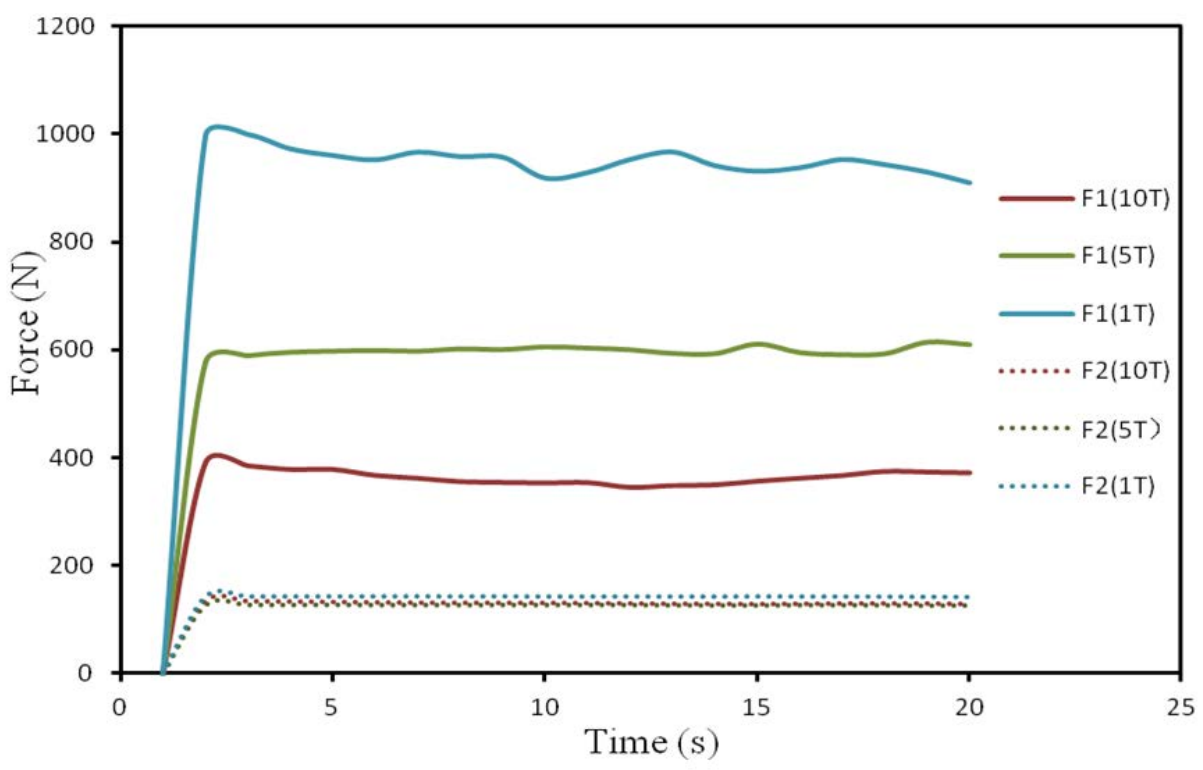

Fig. 3. Force measurement for Material \#1 drawn without lubricant.

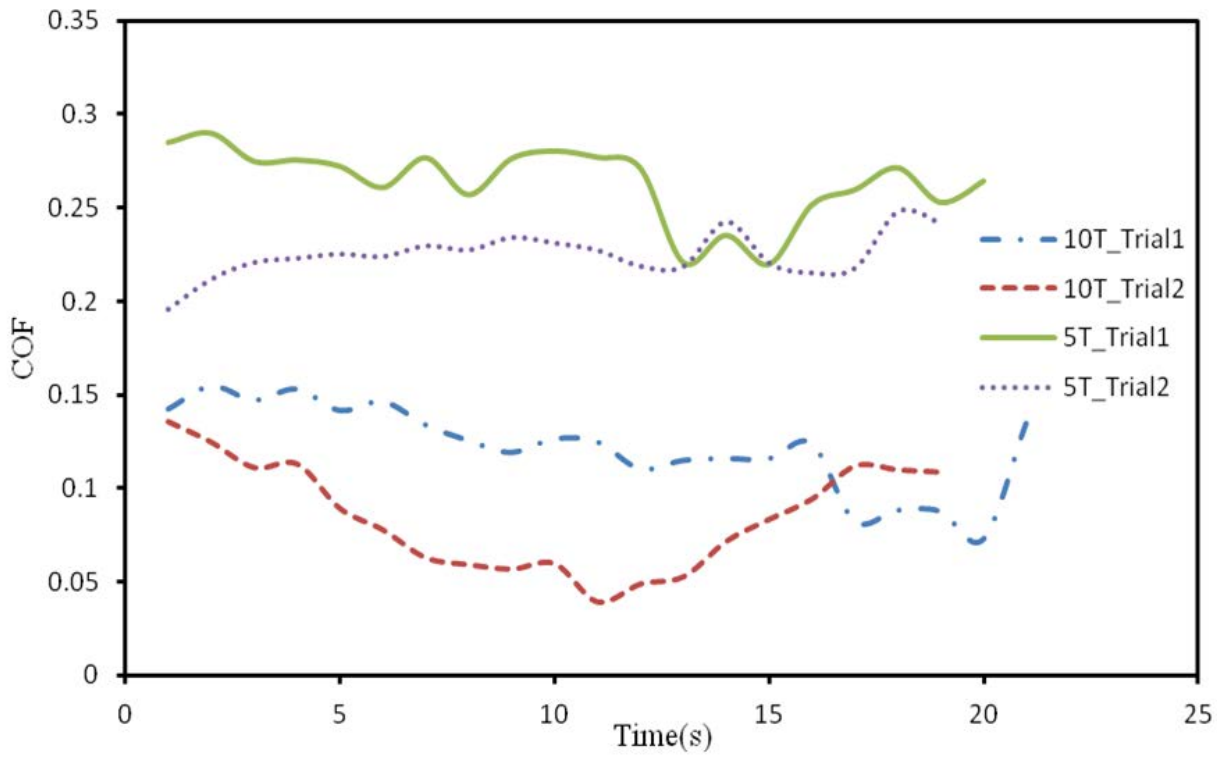

Fig. 4. COF curves for material 1 under dry condition. 


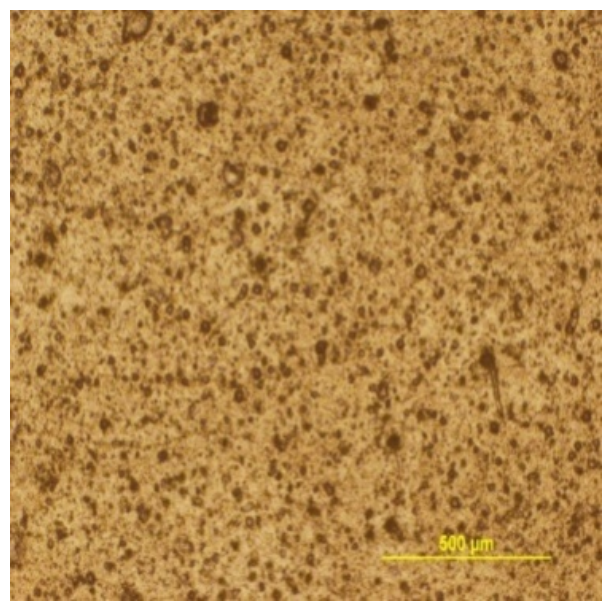

(a) Before test

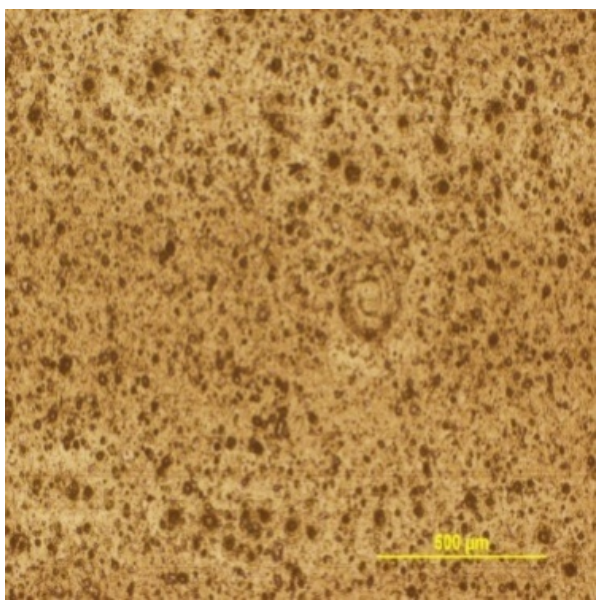

(c) $5 \mathrm{~T}$ die radius

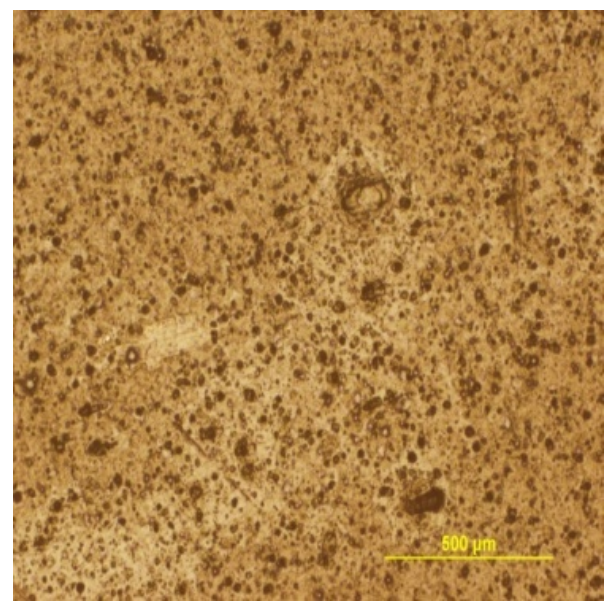

(b) $10 \mathrm{~T}$ die radius

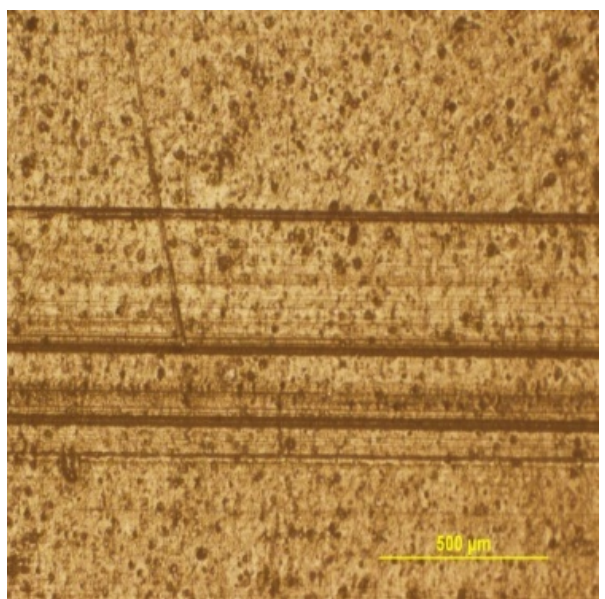

(d) $1 \mathrm{~T}$ die radius

Fig. 5. Optical microscope images of coating surfaces of Material \#1 before and after test (with no lubrication). 


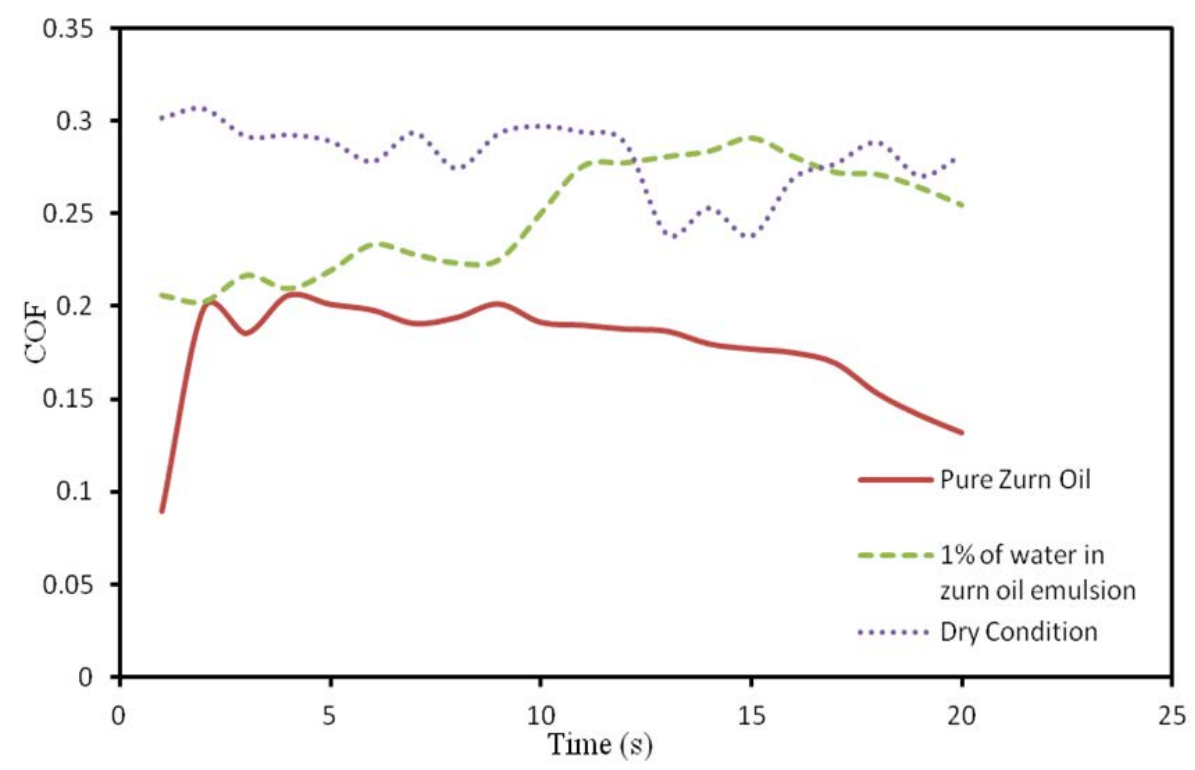

Fig. 6. Coefficient of friction measurement at different lubrication conditions (5T die radius).
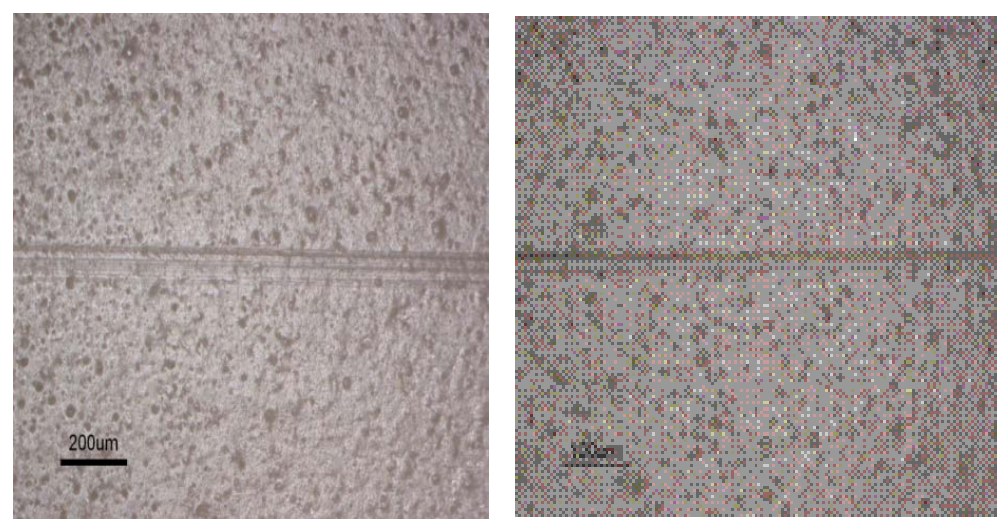

(a) $100 \%$ oil

(b) $1 \%$ oil in water emulsion

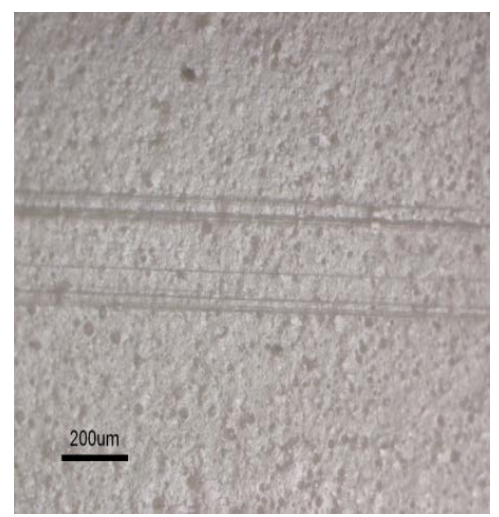

(c) no lubricant

Fig. 7. Optical microscope images of coating surfaces of Material \#1 tested under different lubrication conditions. 


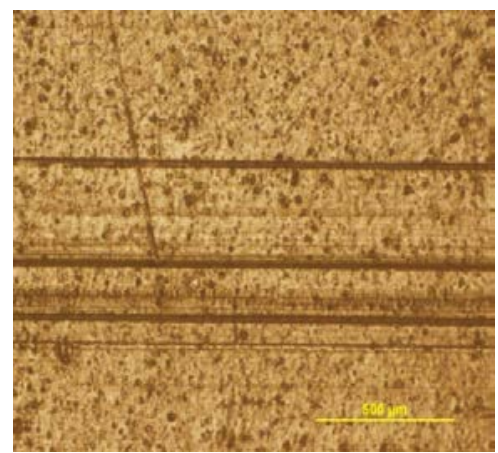

(a) $1 \mathrm{~T}$ die radius

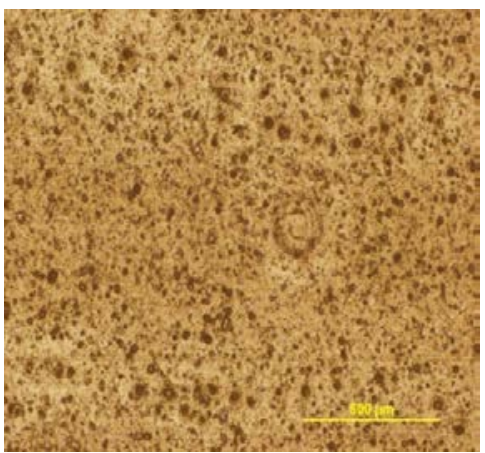

(b) $5 \mathrm{~T}$ die radius

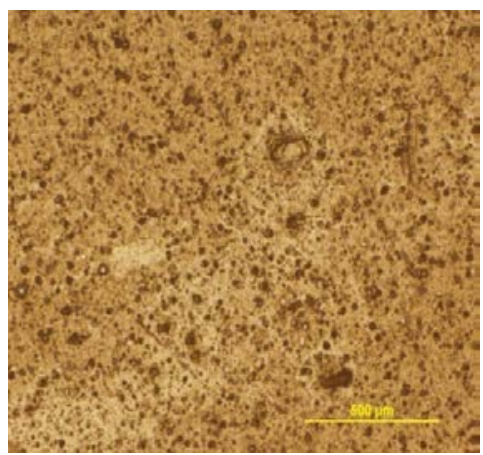

(c) $10 \mathrm{~T}$ die radius

Fig. 8. Coating surfaces of Material \#1 tested under no lubricant condition.

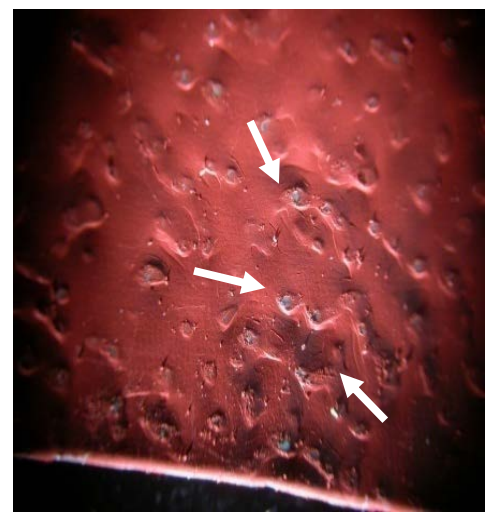

(a) $1 \mathrm{~T}$ die radius

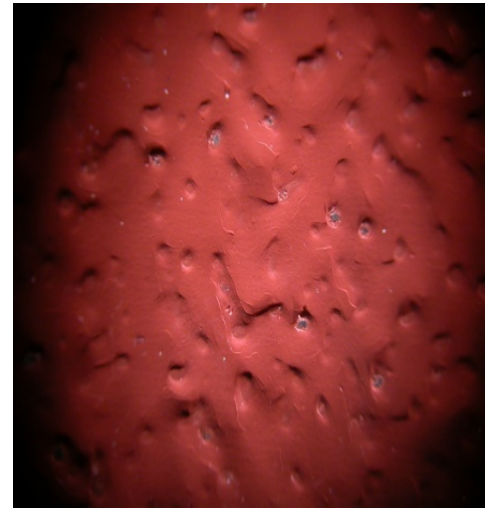

(b) $5 \mathrm{~T}$ die radius

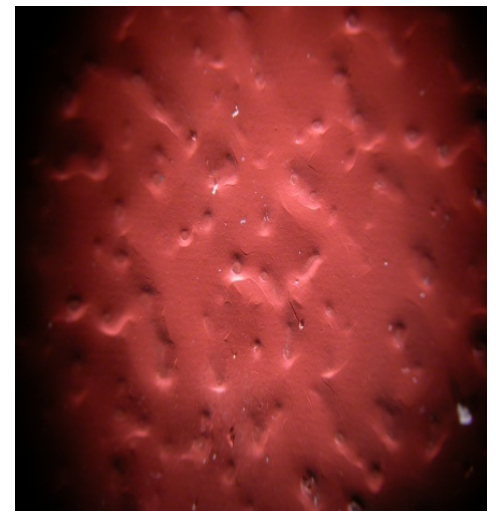

(c) $10 \mathrm{~T}$ die radius

Fig. 9. Coating surfaces of Material \#3 tested under no lubricant condition.

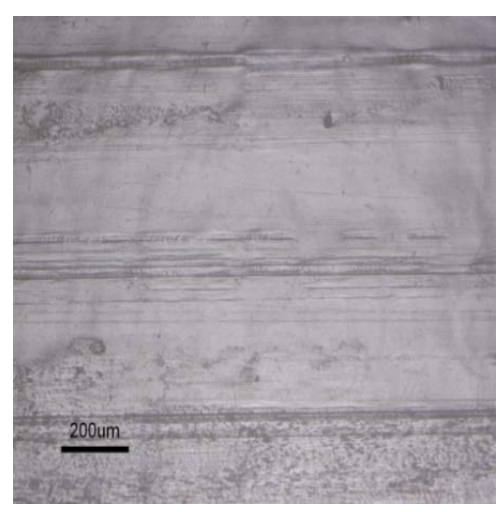

(a) $1 \mathrm{~T}$ die radius

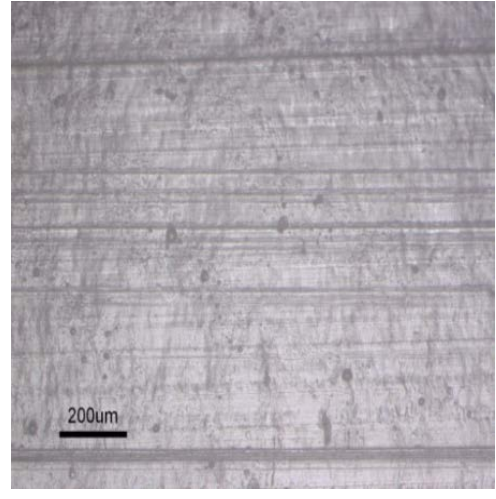

(b) $5 \mathrm{~T}$ die radius

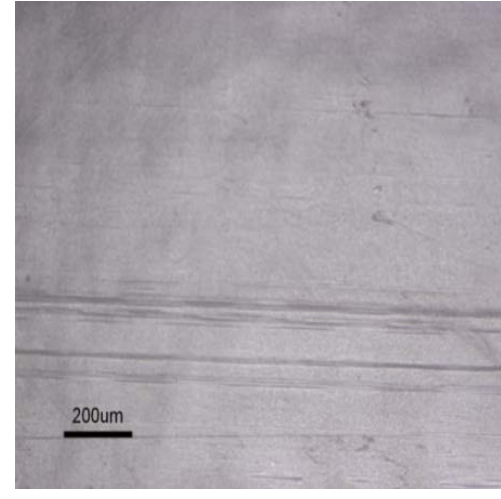

(c) $10 \mathrm{~T}$ die radius

Fig. 10. Coating surfaces of Material \#4 tested under no lubricant condition. 


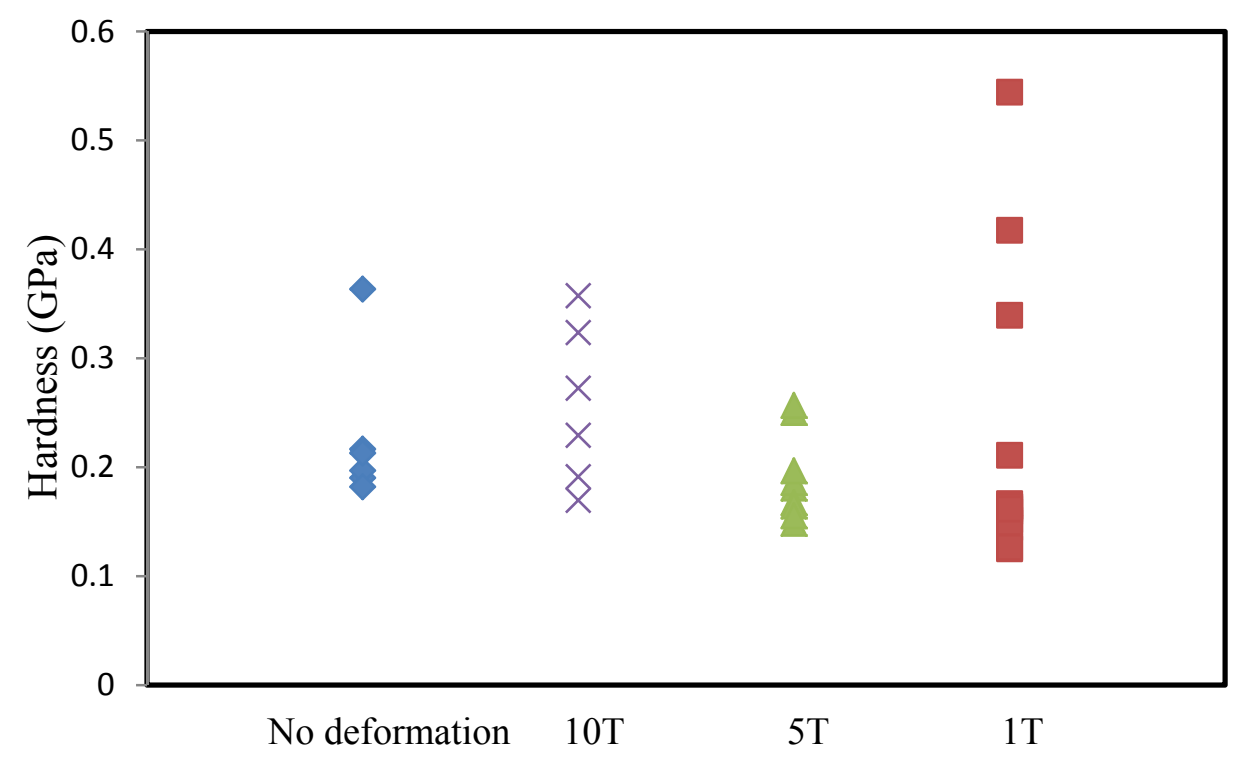

Fig. 11. Nano-indentation results of Material \#1.

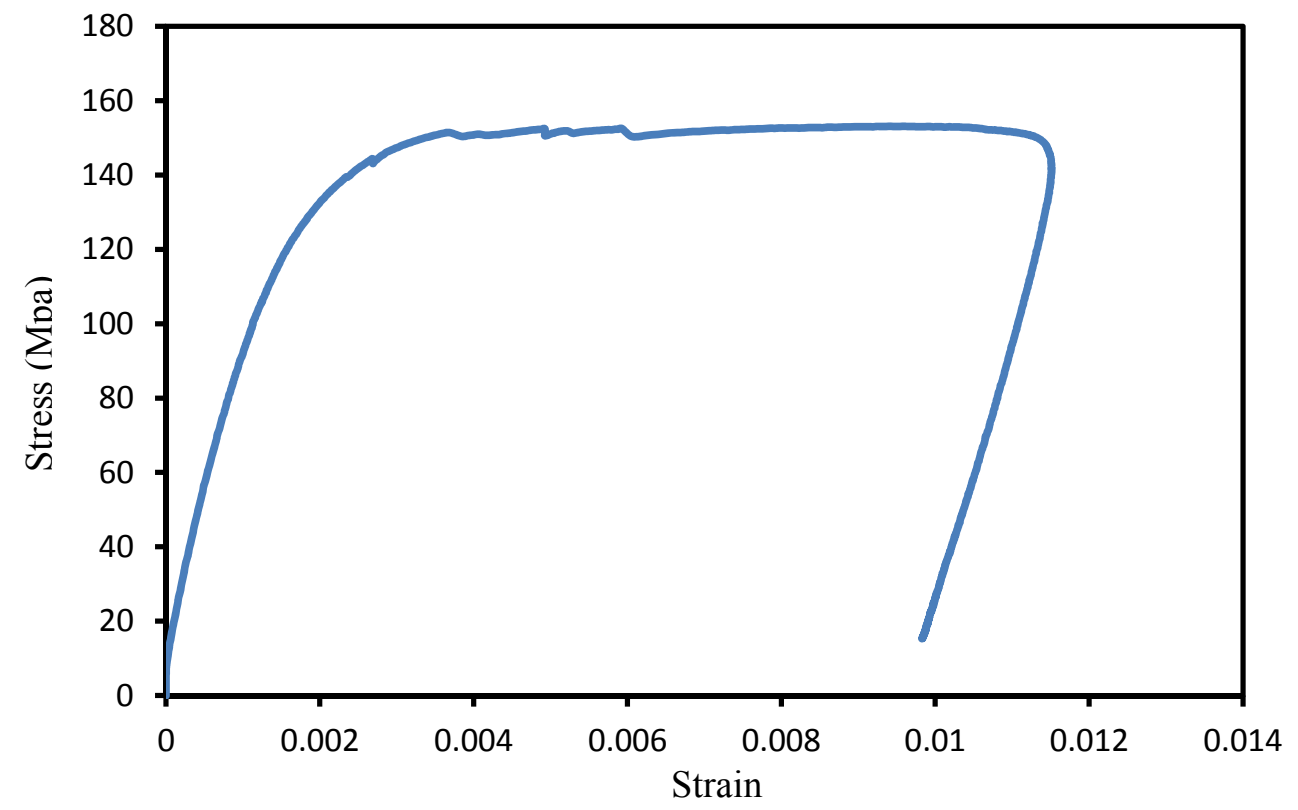

Fig. 12. Tensile test data of the aluminum substrate. 


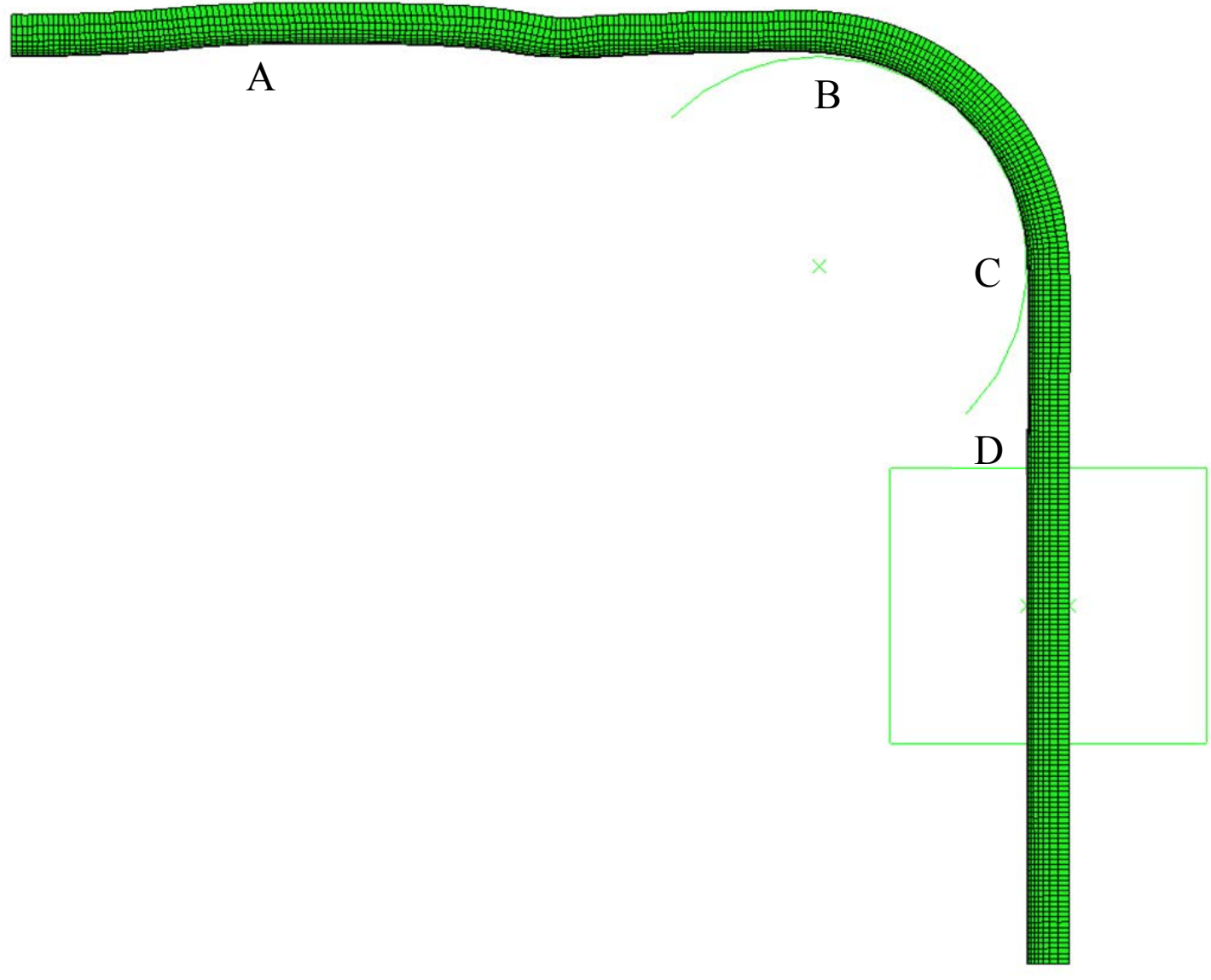

Fig. 13. FEA bending under tension simulation. 


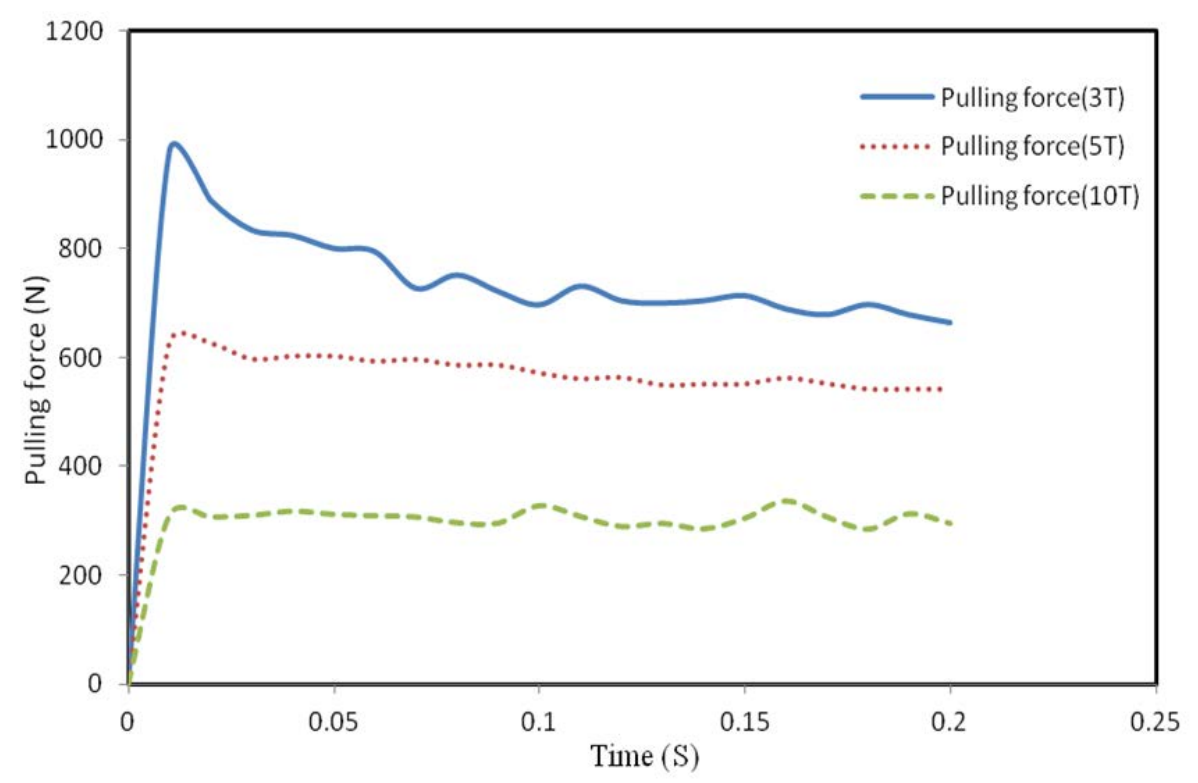

Fig. 14. Pulling forces from bending under tension simulations for die radii of 3T, 5T, $10 \mathrm{~T}$.

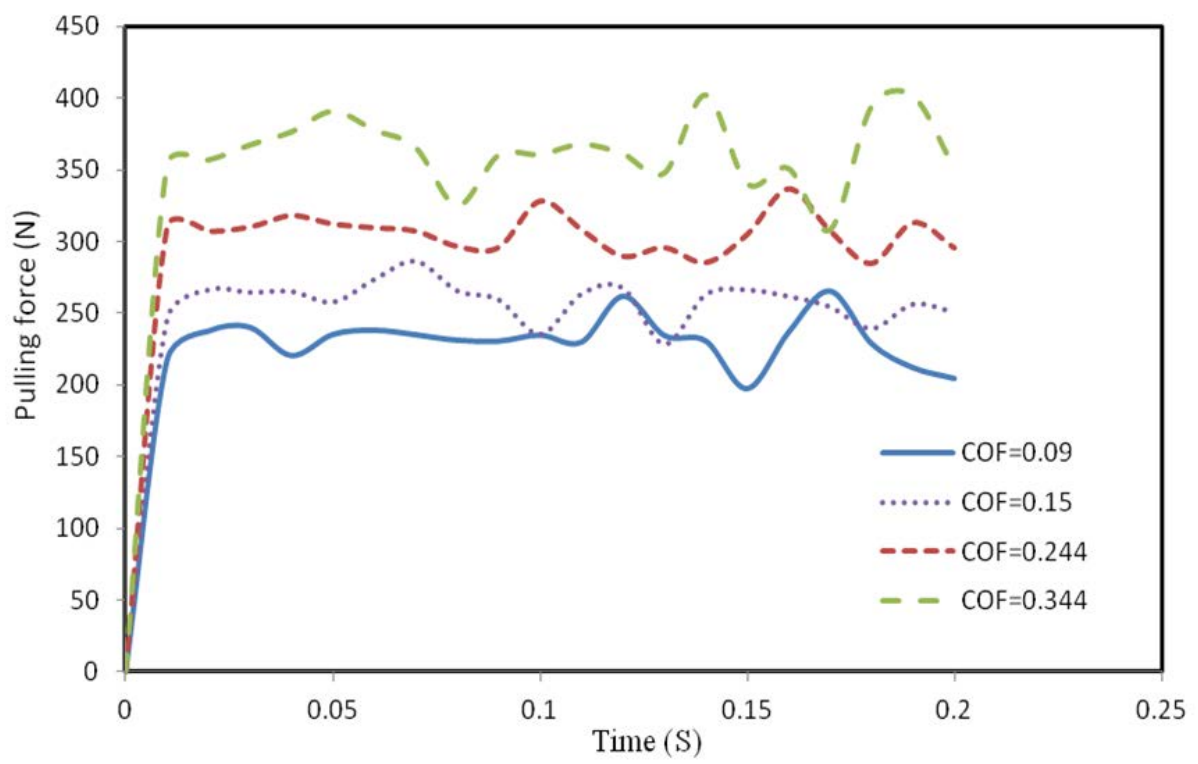

Fig. 15. Pulling forces from bending under tension simulations for different coefficient of friction at $10 \mathrm{~T}$ die radius. 


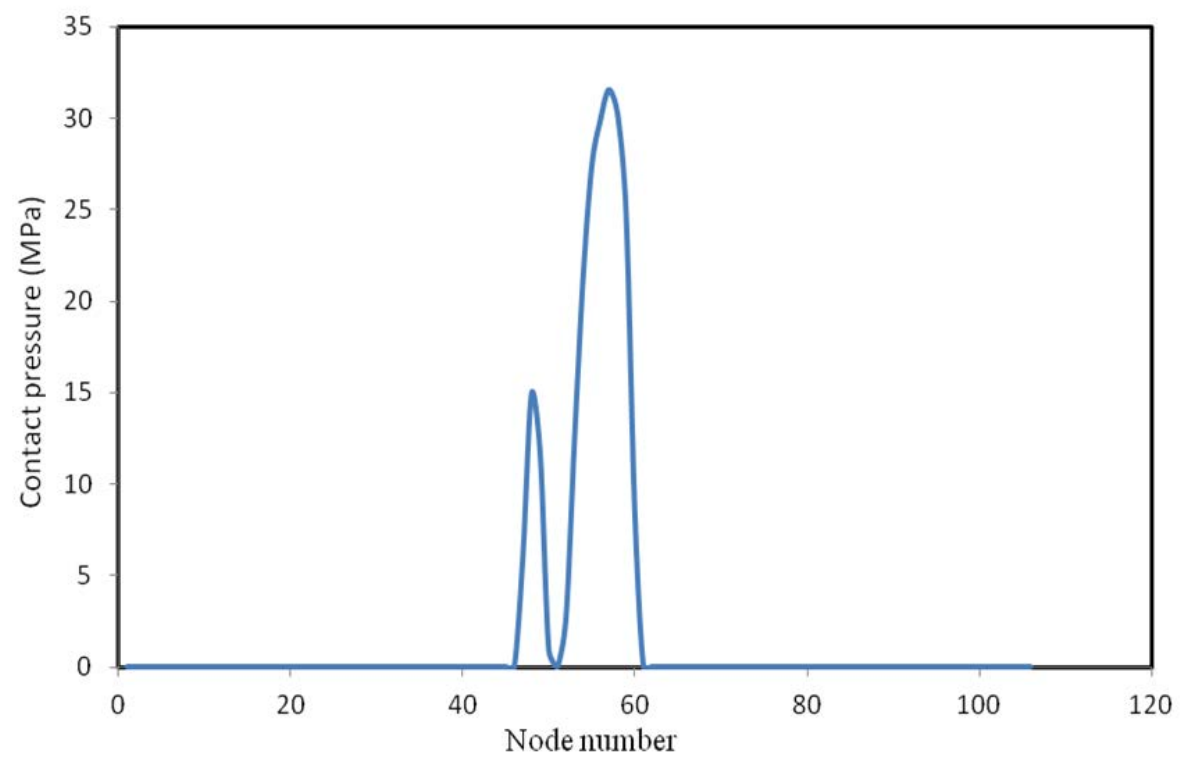

(a) $\mathrm{t}=0.04 \mathrm{sec}$.

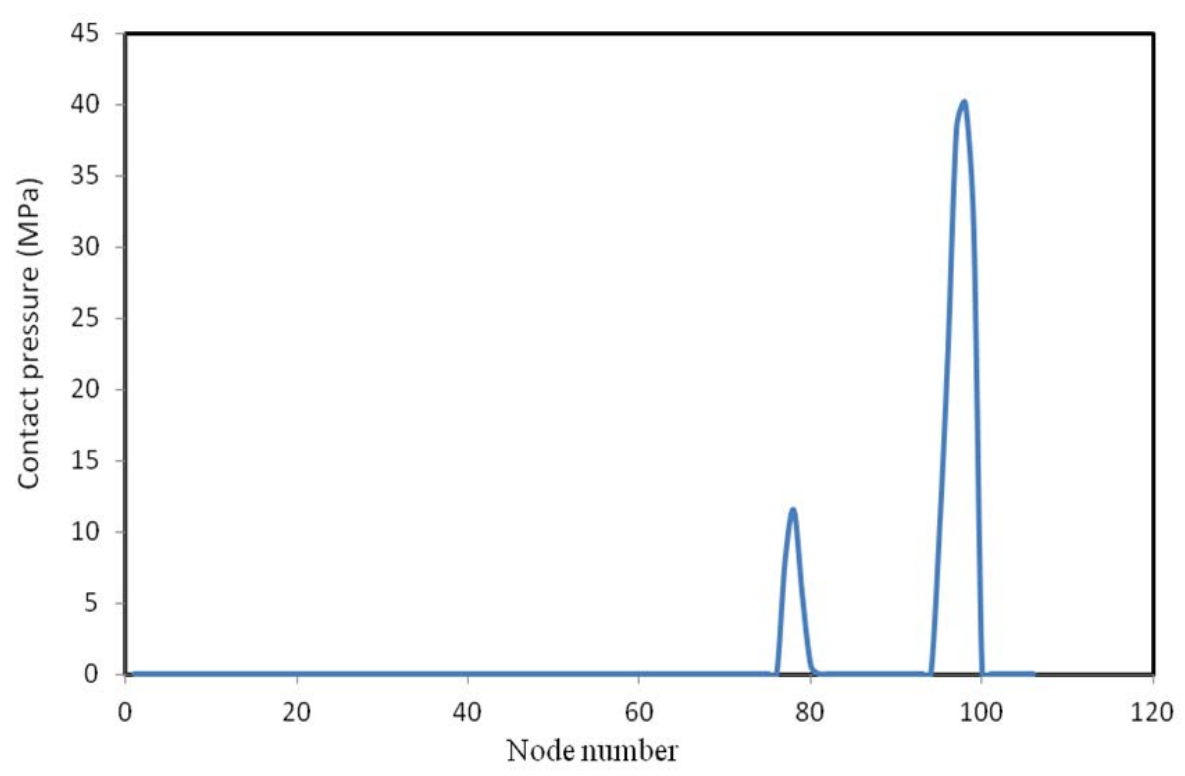

(b) $\mathrm{t}=0.1 \mathrm{sec}$.

Fig. 16. Contact pressure versus nodes at time $t=0.04 \mathrm{sec}$. and $t=0.1 \mathrm{sec}$. for material drawn over $5 \mathrm{~T}$ die radius. 


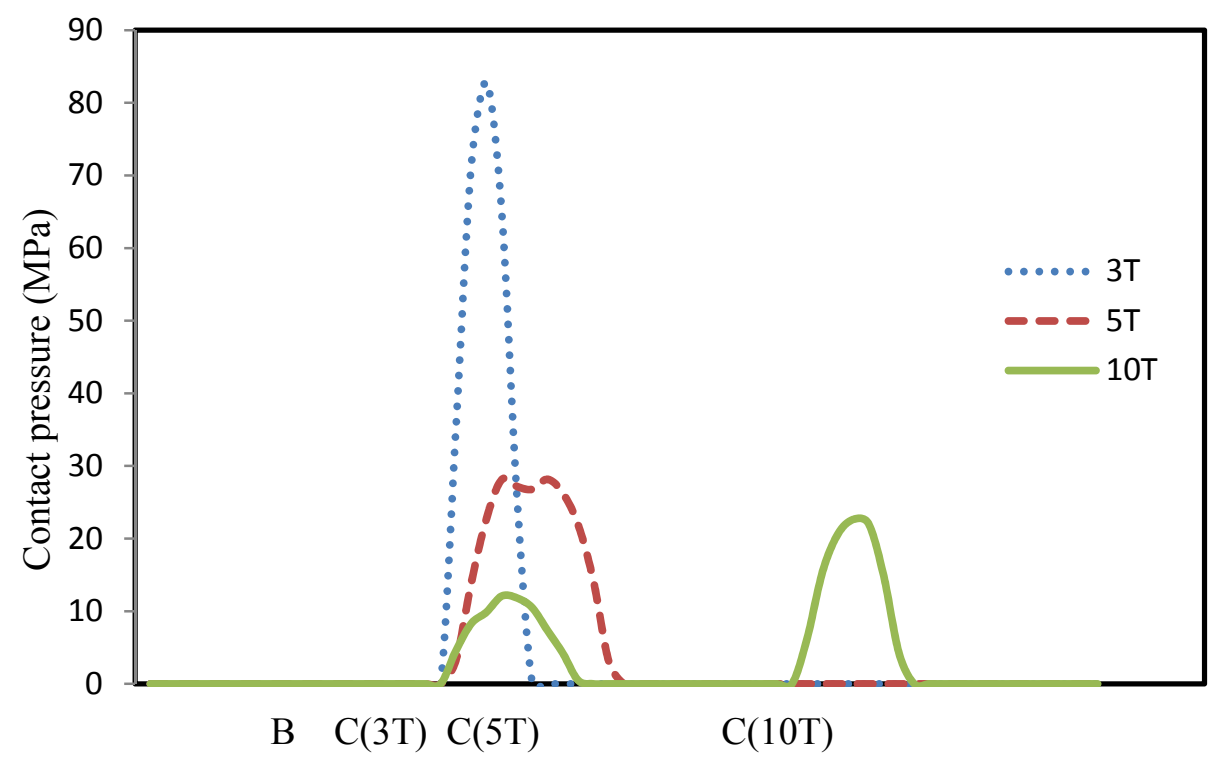

Fig. 17. Contact pressure versus location on the die at time $t=0.08 \mathrm{sec}$. for material drawn over $3 \mathrm{~T}, 5 \mathrm{~T}$ and $10 \mathrm{~T}$ die radius.

Table 1 Materials for testing.

\begin{tabular}{cccc}
\hline Material & Substrate & Coating & $\begin{array}{c}\text { Thickness } \\
(\mathrm{mm})\end{array}$ \\
\hline$\# 1$ & Aluminum 3003 H14 & PVDF & 0.762 \\
\hline$\# 2$ & Galvanized Steel & PVDF & 0.381 \\
& SS37(non-textured) & & \\
\hline$\# 3$ & Galvanized Steel & PVDF & 0.381 \\
\hline$\# 4$ & SS37(textured) & & \\
\hline
\end{tabular}

